\title{
Lightweight Construction is Gaining Momentum
}

The K 2016 event in Düsseldorf came to a successful conclusion at the end of October and just one month later, all eyes will turn to Composites Europe on 29 November at the same venue. The many events included in this year's fair amply reflected the ever-growing importance of lightweight construction.

The "K" event also tackled "upstream" issues, such as how to sustainably obtain polymers given the high cost of energy in Germany and how to secure a smoothrunning supply chain amid the weak Euro and the upturn in demand in the USA and Asia. However, at the "Composites" event the focus will shift from raw material procurement to modern multi-material systems with around 350 exhibitors addressing issues that reach beyond mere synthetics. This year will also see the "Aluminium" event held in parallel, with around 950 exhibitors. Organiser Reed Exhibitions emphasises that the featured exhibition and lecture forum lends this event an interface function connecting metallic and fibre composite technologies in structural components.

The industry is constantly grappling with the issue of how to guarantee quality-assured serial production for complex fibre-reinforced components - something which still represents a hindrance. The first solutions are now on course to be rolled out at Düsseldorf. "In future, we need to ensure serial production with the latest production and automation solutions", added the Event Director of
Composites Europe, Olaf Freier. In this context additive manufacturing is becoming increasingly relevant, even given the slow pace at which the market is emerging - reflecting the lack of uniform quality assurance standards and sub-optimal serial production readiness among others. The topic of Industrie 4.0 seems to be coming on board far faster, which is set to ensure networked production to accelerate manufacturing and thus improve competitiveness in an accelerated world. In Düsseldorf, Reed is expecting around 30,000 professional visitors from industry, research and development.

Many specialist disciplines overlap in the area of lightweight construction. As usual, this volume includes a wide range of themes being addressed by the industry. Please note: This edition of lwd will also be available in English. 3,000 copies are being published in English as a part of the German printrun. From next year it will be available in an exclusively electronic form. We hope this will help us expand our readership and also help meet the international need for information more effectively. The German edition will, of course, continue to be supplied to you in printed form.

Due to the unusual timing of the Composites Europe 2016 event we have scheduled an early publication of the final edition for this year for 18 November. All that is left for me now, is to wish you a successful end of year!

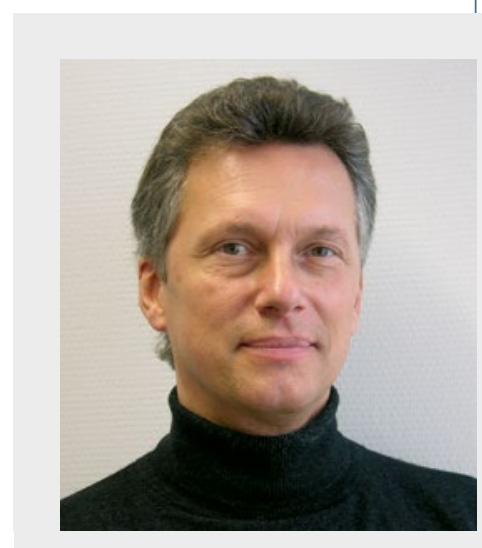

Dipl.-Ing. Ulrich Knorra Editor, ulrich.knorra@springer.com 